\title{
Globe
}

Revue internationale d'études québécoises

\section{Claude Corbo : Les Jésuites québécois et le cours classique après 1945. Montréal, Septentrion, coll. "Cahiers des Amériques ", 2004}

\section{Karine Cellard}

Volume 8, numéro 2, 2005

URI : https://id.erudit.org/iderudit/1000923ar

DOI : https://doi.org/10.7202/1000923ar

Aller au sommaire du numéro

Éditeur(s)

Globe, Revue internationale d'études québécoises

ISSN

1481-5869 (imprimé)

1923-8231 (numérique)

Découvrir la revue

Citer ce compte rendu

Cellard, K. (2005). Compte rendu de [Claude Corbo : Les Jésuites québécois et le cours classique après 1945. Montréal, Septentrion, coll. « Cahiers des

Amériques ", 2004]. Globe, 8(2), 314-317. https://doi.org/10.7202/1000923ar d'utilisation que vous pouvez consulter en ligne.

https://apropos.erudit.org/fr/usagers/politique-dutilisation/ 


\section{REVUE INTERNATIONALE D'ÉTUDES QUÉBÉCOISES}

preuve probante: le Poulin "intertextualisateur "se transforme, chez la jeune génération, en Poulin * intertextualisé *.

En terminant, on ne saurait passer sous silence l'optimisme de Lamontagne, qui célèbre le dynamisme de la littérature québécoise à chacune des pages de son ouvrage. C'est à se demander si l'étude n'est pas un prétexte, certes louable, pour faire la promotion de la littérature québécoise. Au moins l'enthousiasme de l'auteur compense-t-il pour tous ces intellectuels qui ne calculent que les pertes dans la littérature contemporaine. D'un autre côté, si, comme le prétend Lamontagne en conclusion, la production actuelle se décline désormais sous le signe du deuil et de la remémoration, faut-il s'étonner que la critique adopte la même posture nostalgique? Il est par ailleurs ironique que, dans une monographie intitulée Le roman québécois contemporain, le propos se termine sur le constat que, avec Ying Chen, Hélène Monette et Gaétan Soucy, le roman ne "[présente] pas la même continuité, voire la même cohérence dans la rupture "(p. 257) que les œuvres du corpus. Celui qui, en lisant le titre de l'ouvrage, s'attendait (avec raison) à une contemporanéité plus fraîche sera déçu. Il convient donc de poser à nouveau la question qui coiffe ce compte rendu: où en est donc le roman québécois, aujourd'bui?

Viviane Asselin Université Laval

\section{Claude Corbo}

Les Jésuites québécois et le cours classique

après 1945.

Montréal, Septentrion,

coll. "Cahiers des Amériques ", 2004.

Dans La mémoire du cours classique. Les années aigres-douces des récits autobiographiques (2000), le professeur de science politique et exrecteur de l'UQAM Claude Corbo amorçait une réflexion sur la formation humaniste du collège classique, enrichie depuis par la publication de nombreux autres travaux sur l'histoire de l'éducation au Québec. En interrogeant les récits d'apprentissage révélés par les écrits intimes 
d'intellectuels québécois, Corbo se donnait alors une visée éminemment réflexive, celle d'explorer méthodiquement la teneur du cours classique qui l'avait lui-même formé.

Dans ce collège huppé qu'était Jean-de-Brébeuf, comment organisaiton l'enseignement? Comment initiait-on les jeunes aux "humanités classiques "? Quels auteurs lisait-on? Qu'apprenait-on en plus du grec, du latin et de la religion? Quelle place faisait-on aux sciences? Aux réalités sociales? À l'identité culturelle québécoise ? Comment préparait-on les étudiants à une modernité que l'on avait toutes les raisons de redouter ${ }^{28}$ ?

Les Jésuites québécois et le cours classique après 1945 (2004) s'inscrit dans le même projet de "reconnaissance des origines * (p. 16) en restituant la logique éducative et culturelle d'une éducation classique qui a façonné plusieurs générations d'élèves québécois. Essentiellement discursive, l'étude adopte cette fois le point de vue des professeurs et retrace le plaidoyer en faveur du cours classique élaboré par les Jésuites depuis l'après-guerre jusqu'à la mise sur pied du système d'éducation public au cours des années 1960 . La contestation du modèle classique, amorcée dès le début des années 1930, culmine alors dans un débat de société qui porte tant sur le rôle des enseignants laïques et la démocratisation de l'éducation que sur la réforme du programme académique en faveur d'un meilleur enseignement des sciences ou de l'introduction d'une filière d'a humanités modernes ". Appuyée sur une riche documentation composée de revues (Relations, Collège et famille, Bulletin du college et des anciens), de monographies et de rapports sur l'éducation, la synthèse de Corbo constitue un apport précieux à l'histoire intellectuelle et culturelle du Québec en donnant à lire un discours cohérent et vigoureux élaboré au a crépuscule du cours classique . (p. 16), alors que tout semble condamner ce système d'éducation de moins en moins adapté aux nécessités du monde moderne.

Adoptant une posture empathique qui restitue fidèlement le plaidoyer des Jésuites, Corbo ouvre son étude sur deux chapitres généraux exposant la philosophie de l'éducation humaniste et les principaux paradigmes qui la sous-tendent, soit une conception profondément anti-

28. Claude CORBO, La mémoire du cours classique. Les années aigres-douces des récits autobiograpbiques, Montréal, Éditions Logiques, 2000, p. 12. 
moderne de la société et une vision organique du développement physique et intellectuel de l'adolescent. En rupture avec la société contemporaine, perçue comme victime des tentations pragmatiques et matérialistes de la vie américaine, l'éducation classique tentera de former une élite chrétienne désintéressée, "servant "la société selon les impératifs de l'éthique et de la vie supérieure de l'intelligence. Ainsi, la formation humaniste propose la transmission d'une culture générale propre à développer le jugement de l'individu plutôt que d'un savoir technique assimilé à l'éducation libérale utilitaire de tendance anglo-saxonne. Elle repose essentiellement sur l'appropriation du patrimoine occidental forgé par l'Antiquité gréco-romaine et enrichi par l'héritage chrétien, et sur la pratique d'un certain nombre d'exercices liés à l'acquisition des langues mortes. Concordant avec la durée de l'adolescence, le cursus des huit années d'humanités classiques s'inspire de l'histoire de la civilisation occidentale pour faire "revivre "à l'étudiant le cheminement intellectuel de la tradition à laquelle il appartient : "Il y a donc un ordre pédagogique dans l'utilisation des genres littéraires, qui est fondé sur l'ordre historique et psychologique normal de leur apparition. Poésie, rhétorique, philosophie correspondent à des phases de l'adolescence de l'humanité et de l'homme ${ }^{29}$ [...]. .

Les grands principes soutenant l'éducation classique ainsi explicités, la suite de l'ouvrage sera consacrée à l'examen systématique des composantes institutionnelles qui en régissent le cadre et le contenu. Le lecteur sera d'abord initié au collège privé comme structure, que les Jésuites souhaitent autonome tant au plan académique qu'au plan financier ; au programme d'études et à l'économie des disciplines, transcendés par une perspective chrétienne qui teinte tous les apprentissages; aux exercices traditionnels (prélection, traduction, écriture et composition, lecture) et à leur logique éducative propre ; à la posture exemplaire de l'enseignant, qui doit constituer en toutes choses un modèle pour l'étudiant ; enfin, aux " périphériques éducatifs " qui font partie de la vie au collège : bibliothèque, clubs scientifiques et autres activités physiques ou religieuses. Malgré la linéarité du plan, l'exposition de l'argumentaire des Jésuites semble progresser de manière circulaire, portée par la réitération des principes -somme toute peu nombreux-qui donnent toute sa

29. Raymond Bourgaul, s.j., * Le cours classique et l'histoire de l'Humanité ", Mélanges sur les bumanités, Québec, Presses de l'Université Laval et Paris, Librairie J. Vrin, 1954, p. 127 ; cité dans Claude CorBo, op. cit., p. 51. 


\section{RECENSIONS}

cohérence à l'éducation classique. En effet, par-delà la diversité des informations et des exemples discursifs convoqués dans l'ouvrage, c'est surtout une philosophie de l'éducation que transmet l'ouvrage de Corbo, toutes les composantes du collège classique étant soumises à une logique argumentative extrêmement prégnante et configurante.

Malgré la richesse de cette démonstration, le lecteur en sortira un peu agacé par la redondance des principes pédagogiques, répétés à la fois dans les mises au point synthétiques qui ponctuent l'ouvrage et dans les chapitres ultérieurs, qui en proposent autant d'applications différentes. Dans la même perspective mimétique, le chercheur adopte aussi le caractère éminemment abstrait du discours dont il s'inspire : en effet, l'ouvrage s'en tient surtout au plaidoyer théorique des Jésuites sans insister sur la pratique effective de l'enseignement classique de l'époque ou sur les remises en question auxquelles prétend répondre ce déploiement rhétorique. Claude Corbo entretient visiblement un grand respect pour cette défense des humanités classiques, menée avec "ténacité, passion et aussi beaucoup de force intellectuelle et d'envergure conceptuelle. (p.9); aussi sa démarche se maintient-elle dans une perspective documentaire et archéologique qui suspend tout jugement, sans pour autant céder à l'apologie ou à la nostalgie. Les Jésuites québécois et le cours classique après 1945 plaira au lecteur curieux qui souhaite mettre en perspective les débats pédagogiques contemporains et sera particulièrement utile au chercheur qui tente de comprendre la formation académique de l'élite canadienne-française d'une époque encore récente. Pour compléter le tableau et mieux juger de l'efficacité de l'argumentaire jésuite, on se reportera à l'anthologie sur les débats pédagogiques de la période publiée par Corbo en $2000^{30}$.

Karine Cellard Université de Montréal

30. Claude CoRBo, Repenser l'école. Une antbologie des débats sur l'éducation du Québec de 1945 au Rapport Parent, Montréal, Presses de l'Université de Montréal, 2000. 